\section{Brain Damage in Children}

\author{
By Dr. Ruth Clark
}

Perhaps one of the most neglected areas in the whole field of brain damage is one in which the damage is minimal and diffuse. More and more we are beginning to realize that slight brain damage may be the cause of some types of learning disabilities, behavior problems and even juvenile delinquency: When we talk about brain-injured children, much of the nomenclature is confused and ambiguous. Perhaps the following definitions will help clarify some of the terms used:

1. Congenital is a time-of-occurence concept. It means that the condition was present at the time of birth. It has nothing to do with heredity.

2. Heredity is a causal concept and indicates that the present characteristics are a result of the condition of the germ plasm.

3. Endogenous is usually used in relationship to mental retardation and indicates that the condition is hereditary.

4. Exogenous usually refers to the type of mental retardation that is not from heredity but from injury to the organism during the pre-natal, neo-natal or postnatal period. Some authors use the term to indicate brain injury that is acquired but does not necessarily make the child mentally deficient.

5. Mental Deficiency can be primary, i.e. of the endogenous type, or secondary, the exogenous type and merely means that the individual is intellectually functioning below the average. Brain injury can cause mental deficiency.

6. Amentia means without or lacking mentality and therefore, refers to mental deficiency. This term is further divided into:

:' Primary Amentia - one whose familial background indicates a history of hereditary deficiency, and

Secondary Amentia - an acquired condition.

7. Cerebral Palsy is a result of brain injury. It is not a disease but a syndrome. in which neuro-muscular dysfunction is the outstanding symptom. Cerebral Palsy is a term applied to a disturbance of motor function resulting from damage to the brain before, during or after birth. It connotes a group of conditions.

These conditions are very different, and consequently, the treatment of the different types of cerebral palsy requires totally different techniques.

8. Dysphasia and Aphasia are language disturbances. They are disorders of symbolic formulation and expression, and are a result of damage or lack of maturation of the associational areas of the brain. The dysphasic's failure to properly use the word "pencil" is not due to a motor disability but rather to a failure in associating and integrating three different aspects of the "ipencil",; that is, the pencil as: (1) a real object of senses of sight, sound, smell, touch, etc.; (2) the sound of the word "pencil" which by convention has come to represent the real object and (3) the neuro-muscular reaction involved in uttering the spoken word " pencil".

Since reading, writing, und $\epsilon$ rstanding and use of objects are associated with language, these skills may also be deficient when an individual suffers disturbances in the associational areas. Aphasia and dysphasia like cerebral palsy are not diseases themselves; they are a symptom of a diseased process and are not essentially a speech problem, but rather a language disorder. Since deaf children have language problems, aphasic children are frequently confused with deaf children. With the deaf, sounds are not heard; with the aphasic, sounds are heard but they are not translated into meaning.

9. Emotional Disorders are many times confused with mental deficiency, deafness and aphasia. While there is always, ${ }^{\circ}$ or practically always, a psychological component accompanying the above-mentioned conditions, there can be emotional disturbances without brain damage of any sort.

If the above terms are kept clearly in mind and appropriate diagnostic instruments used to determine the real difficulty: : with children presented at speech clinics, therapy much.more appropriate for the individual case can be: instigated. While present diagnostic instruments are not refined enough in many cases to enable us to. see the complete and accurate picture of children presented for therapy, they give us a -better picture than we could otherwise obtain, and if we are aware of their limitations, we can more easily avoid the pitfalls that we might encounter if we were not forewarned.

Many children suffering from the conditions referred to above are recógrized and usually some type of provision is made in their training for their particular handicap. "However, the child who has a very slight, non-localized brain injury frequently is not recognized and yet, he may have certain difficulties for which special allowances should be made. He with the more easily-recognized brain-injured child, is apt to have perceptional," thinking and behavior difficulties. This minimal, diffuse brain injury results from many causes such as the mother running a high temperature before the child's birth, oxygen starvation before or during or after birth, severe childhood diseases, and almost any condition that will cause cerebral palsy or secondary amentia.

\section{CHARACTERISTICS OF BRAIN INJURY}

Any serious student in this area realizes that there is a great deal of confusion regarding the characteristics 
of brain-injured children. Probably one reason is that the literature pertaining to the field emanates from many different areas and frames of reference. Among personnel contributing to the literature are Speech Pathologists, students of mental deticiency, specialists from several areas in Psychology and medicine, as well as educators.

In spite of the confusions in the field, the following characteristics of brain injury are fairly well accepted by the different writers:

1. Brain lesions produce similar behavior regardless of the location of the lesions.

2. Rigidity and perseveration - this refers to the inability to change easily from one "mental set" to another and the tendency to continue an acceptable performance.

3. Perceptual difficulties - Perception is the mental process which gives particular meaning and significance to a given sensation and therefore, acts as a preliminary to thinking. One basic characteristic of perceiving is that a perception is made as a whole, "all at once and nothing first". This power of integration is dependent upon an intact nervous system. Brain injured children are frequently so attracted to minute details that they disregard the conceptual concept as a whole. Some writers refer to this as forced responsiveness. Such a reaction is exemplitied by the child who is so attracted by a pretty button on a dress that he reacts to this unessential factor alone, disregarding the essential factors in his environment. Sometimes labeled as "inattentiveness," it is really the exact opposite: a complete attentiveness (to something which the normal person would not notice, and therefore an inattentiveness to everything else).

4. Thinking Disorders - Clinical observations of these children have yielded evidence of peculiarities in thinking reasoning, and concept formation deviation markedly from the normal. The brain-injured child is easily prone to give responses which are uncommon, far-fetched, and often peculiar. $\mathrm{He}$ is attracted more easily by unessential and accidental details, relationships between object and picture are drawn vaguely, situations are imagined which extend beyond the present situation.

5. Behavior Disorders and Disinhibition: Some studies have shown brain-injured children to be erratic, uncoordinated, uncontrolled, uninhibited and socially unaccepted. They are apt to have extreme mood swings and while laughing and playing, burst into explosive crying when confronted with a difficulty.

\section{DIAGNOSIS}

The difficulties of properly diagnosing a child having minimal diffuse brain damage are many. Frequently, the difficulty lies deep in the cerebrum and does not show up on an Electro-encephalograph recording or in a neurological test. Many times the only way a child can be classified as having minimal diffuse brain damage is by ruling out every other possibility. The problems of diagnosis are too manifold to be discussed nere. But it is this difficulty which has caused so many children who are probably slightly brain-injured to be classified as hard of hearing, mentally defective, problem children or psychotic. These children then receive therapy that is not structured for their true needs. Diagnosis of the minimally brain-injured is one of the most challenging problems in the field today.

When confronted with a child having perceptual thinking or behavior problems for which we can find no etiology nor reason, we might well consider the possibility of diffuse brain damage of a minimal amount. In that case different therapeutic procedures will be used than would be if we were working for example, with a behavior problem without any organic background or with a mentally retarded child of the familial type.

\section{THERAPY FOR THE BRAIN-INJURED CHILD}

Therapy is based upon controlling and helping the child to control the perceptual, conceptual and behaviorial problems which clinical observation and research have indicated to be peculiar to the braininjured child. The stimuli of an ordinary environment are simplified so that the child can build up a threshold of endurance to them. A few points for the speech therapist to keep in mind when working with braininjured children follow:

1. Keep environmental stimuli reduced.

(a) Few, if any, pictures or decorations on walls.

(b) Quiet room.

(c) All materials put away that are not in use.

(d) Furniture placed so as to give sense of space.

2. Insofar as possible, use concrete objects and concrete words when beginning therapy.

(a) Dean is an example: In teaching him the names of knife, fork, and spoon, the clinician had little success when she used pictures; as soon as she took him over to the dining room for his speech lesson and had him use actual utensils, learning progressed.

3. Keep materials simple.

(a) Pictures which contain too much will be overstimulating.

(b) Toys should not involve many different actions.

4. Lessons should involve motor activity.

(a) This is true of therapy with all young children, but especially so with brain-injured, since it reduces the distractibility. 
5. Many of the children need training in auditory recognition and amplification of sound should help in this respect.

(a) They perceive words as a whole, and can not isolate parts.

6. Mirror work may be helpful.

(a) May involve too many distractions.

7. Moto-kinesthetic cues have been found to be helpful.

8. Probably no group therapy for a while.

9. If a child can read or write, these skills can be used in helping him speak.

10. Many of the child's emotional needs can be met in speech therapy - make him feel secure and adequate.

11. Always keєp in mind the Organismic approach and remember that anything that affects a part of the organism will affect the organism as a whole.

12. If a child is tending to perseverate, quietly shift to another, completely different activity, rather than attempting to continue that one.

13. Music and rhythms may be of great advantage.

14. Strauss and Lehtinen feel that the use of situations such as a store, post office, or bank is not propitious with brain-injured children in academic education, since they involve many distractions and excitations with which he can not cope. This does not mean that learning by doing is not useful, but it need not be in terms of life situations; range of activity should be small. Although there seems to be no literature on the subject, it is probable that situational frames of reference should not be employed in speech therapy.

\section{CONCLUSIONS AND IMPLICATIONS}

Since the etiology and diagnosis of minimal diffuse brain damage is not clearcut and positive, the possibility of such a diagnosis might be considered when children with behavior problems, thinking and perceptual problems are presented to the speech clinic With this consideration therapeutic procedures will be quite different than they would be if there was not a possibility of brain damage.

It is the author's belief that many children having slight brain injuries and classified as "ornery" or "spoiled" are not understood and may try to receive response by causing disturbances. If these children can be diagnosed and can be provided with a controlled environment and proper therapy, a part of our juvenile delinquency problem may be solved.

\section{㫰}

BIBLIOGRAPHY

1. Frazeur, H. A. and Hoakley, P., "Significance of Psychological' Tes Results of Exogenous and Endogenous Children," American Journal of Mental Deficiency, 51:384-388, 1947 .

2. Goldstein, Kurt, "Concerning Rigidity," Character and Personality $11: 209-226,1942-3$

3. Jellinek, Augusta, "Phenomena Resembling Aphasia. Agnosia, and Apraxia in Mentally Defective Children and Adolescents," Journal of Speech Disorders, 6:51-66. 1940

4. Nance, Lorna S. "Differential Diagnosis of Aphasia in Children," Journal of Speecti Disorders, 11:219-224, 1946.

4. Strauss, Alfred A.., and Lehtinen, Laura E., Psychopathology and Education of the Brain-Injured Child, Grune \& Stratton, N.Y., 1950.

6. Sirauss, A. A. and Werner, H., "Disorders of Conceptual Thinkin: in ihe Brain-iniured Child," Journal of Nervous Mental Disorders,

7. Wallin. J. E., Ch.ldien with Mental and Physical Handicaps, PrenticeHall, Inc. N.Y., 1949

8. Werrer, H.. "The Concept of Rigidity: A Critical Evaluation," Psychological Review, 53:43, 1946.

By Ruth M. Clark. Ph.D., Associate Professor and Director, Children's Speech Clinic. University of Denver. 2045 So. York Street.

Dr. Clark is an honorary member of the South Africa Logopedics Society, and lectured at the University of Witwatersrand 1950-1951. 